\title{
Discutindo as potencialidades dos vídeos tutoriais para a utilização em educa- ção a distância
}

Discussing the potentialities of video tutorials to distance learning

\author{
Josiane Dal Forno ' \\ IProfessora Adjunto - NTE/CE - UFSM - josiane.dalforno@gmail.com
}

\section{Resumo}

Observa-se que os professores, de modo geral, utilizam de forma limitada os recursos disponíveis no ambiente virtual de aprendizagem (AVA) e também outros externos a ele que poderiam ser inseridos neste ampliando as possibilidades formativas oferecidas tanto do ensino presencial, quanto da educação a distância. Assim, este artigo tem como objetivo apresentar o processo de construção de vídeos tutoriais e discutir a sua utilização em atividades pedagógicas nas diferentes modalidades educativas. Para realização deste trabalho, utilizou-se, num primeiro momento, de pesquisa bibliográfica a respeito dos principais assuntos envolvidos na produção e uso dos vídeos tutoriais. Para compreender e fomentar o uso vídeos tutoriais como recursos educacionais por professores de ensino superior, na educação a distância e no ensino presencial, partiu-se para a criação de alguns vídeos. O processo de criação de um vídeo tutorial envolve diferentes etapas e conhecimentos específicos, sobretudo quanto às características e potencialidades de diferentes softwares.

Palavras Chave: vídeos tutoriais; recursos educacionais; educação a distância

\begin{abstract}
It is observed that teachers, in general, use of a limited available resources in the virtual learning environment (VLE) and others external to it which could be inserted in this expanding training opportunities offered both classroom teaching, as distance education. Thus, this paper aims to present the process of construction of tutorial videos and discuss its use in educational activities in different educational modalities. For this study, we used, at first, a literature about the main issues involved in the production and use of video tutorials. To understand and promote the use tutorial videos as educational resources for teachers of university teaching, distance education and classroom teaching, broke for creating some videos. The process of creating a video tutorial involves different steps and specific knowledge, especially concerning the characteristics and potentials of different softwares.
\end{abstract}

Keywords: video tutorials, educational resources, distance education 


\section{INTRODUÇÃo}

Sabe-se que a utilização de recursos educacionais em sala de aula pode contribuir para fomentar a aprendizagem dos estudantes. Contudo, percebe-se que, muitas vezes, a escolha do recurso a ser usado é feita em função daqueles que já são mais conhecidos e comumente usados pelos professores, como lousa e giz, retroprojetor e, mais atualmente, o data-show, no que diz respeito ao ensino presencial.

Já na educação a distância pode-se dizer que o uso de diferentes recursos é uma necessidade constante, que obriga os docentes a fazer uso de novas ferramentas cotidianamente. No entanto, isso não significa que todos os envolvidos, sobretudo professores e tutores, saibam utilizar com competência os mais diversos recursos. Muitos não sabem sequer fazer uso daqueles que já estão disponíveis no ambiente virtual de aprendizagem, e cometem alguns equívocos que comprometem a aprendizagem dos estudantes.

Observa-se que os professores, de modo geral, utilizam de forma limitada os recursos disponíveis no ambiente virtual de aprendizagem (AVA) e também outros externos a ele, que poderiam ser inseridos neste, ampliando as possibilidades formativas oferecidas tanto do ensino presencial, quanto da educação a distância.

Além disso, a educação a distância apresenta especificidades que precisam ser consideradas pelos professores nas diferentes etapas do processo educacional, desde a elaboração do planejamento até o desenvolvimento das atividades didáticas. Sabe-se ainda que a atuação docente, nessa modalidade, exige do professor habilidades e conhecimentos específicos, para além dos que possui e usualmente aciona ao lecionar em uma sala de aula presencial.

Diante disso, torna-se relevante criar condições para que os professores aprendam a utilizar os recursos disponíveis e possam, com isso, desenvolver a autonomia necessária para a produção de alguns destes, principalmente daqueles que podem ser facilmente associados ao AVA.

Nota-se que há ainda uma grande necessidade de produção de ferramentas que auxiliem o professor em suas atividades docentes, sobretudo na preparação de materiais didáticos e recursos educacionais adequados aos conteúdos disciplinares, que possam facilitar a aprendizagem dos estudantes.

No que se refere ao âmbito externo, percebe-se cada vez mais a necessidade de produção de recursos educacionais que possam ser acessados por usuários em qualquer parte do mundo, via internet.

Assim, este trabalho teve como objetivo criar tutoriais em vídeo para orientar a produção de recursos, como blogs e vídeos, pelos próprios professores, como forma de ampliar o modo de trabalhar os conteúdos específicos das disciplinas com os alunos e diversificar as atividades pedagógicas de acordo com as características de cada turma/curso.

\section{FORMAÇÃO DOCENTE, EDUCAÇÃO A DISTÂNCIA E TECNOLOGIAS}

Vivenciamos atualmente um contexto de evolução tecnológica que nos permite adquirir bens que há poucos anos nem sequer poderíamos imaginar. Essa evolução, entre ouras coisas, alterou as demandas atuais sobre a formação dos profissionais de todas as áreas para atender às necessidades de um mercado em constante transformação.

Nessa direção a formação dos professores tem sido o foco de diversas críticas pela dificuldade que estes enfrentam em fazer a correspondência entre o que aprendem nos cursos de graduação e pós-graduação e o que precisam ensinar aos seus alunos, cada vez mais diversos e "conectados" às transformações.

Ser professor atualmente tem implicado uma série de reflexões em torno, sobretudo, da qualidade que se deseja propagar na educação de crianças e jovens para que possam ter condições de vivenciar experiências significativas de aprendizagem, considerando as atuais demandas do mercado, que direta ou indiretamente, definem opções e delimitam espaços formativos. Diante disso, o professor se vê, muitas vezes, despreparado para enfrentar situações novas que lhe exigem conhecimentos não disponíveis em seu repertório.

O desafio é ainda maior quando se pensa na formação de professores capazes de ensinar esse novo aprendiz, conectado a internet, com uma imensidão de informações a sua disposição ao menor clique no mouse. Diante disso, cabe questionar como ensinar alunos "conectados"? Quais recursos os professores podem utilizar para que os alunos aprendam mais facilmente?

Assim, formas tradicionais de ensinar precisam ser revistas para atender às necessidades formativas destes alunos. Por outro lado, é preciso ter em conta que também os professores necessitam aprender, que precisam conhecer novas alternativas para desempenhar o seu trabalho de modo mais coerente e efetivo no atual contexto. 
Diante da velocidade com que a evolução tecnológica vem mudando nosso modo de viver, a busca por informações atualizadas, por novos conhecimentos tem causado preocupação aos professores de modo geral, que necessitam descobrir novas formas de ensinar e de aprender.

Vivemos na sociedade da informação, e isso implica um processo de aprendizagem constante para articulação de conhecimentos provenientes de diversas fontes, produzidos individual e coletivamente.

Com isso o papel do professor muda significativamente e novas possibilidades de aprendizagem são criadas e difundidas, por exemplo, por meio da educação a distância. Esta modalidade traz novas possibilidades, não só para a formação dos alunos em cursos de graduação, mas também, dos próprios professores que os acompanham no ensino superior.

Além disso, segundo Pedrosa (2003) pode contribuir para que professores vençam as barreiras de tempo, espaço e falta de recursos financeiros, pois a educação a distância pode oferecer oportunidades também àqueles que apesar de próximos a esses grandes centros não contam com condições para dar continuidade a sua formação.

Nessa direção vale acrescentar o que Pesce (2002, p. 102) ao se referir às possibilidades de formação continuada em serviço, ressalta sobre a educação a distância como sendo um precioso instrumento para a formação de educadores quando:

- não situe o educador como mero reprodutor do conhecimento construído por outrem, mas ao contrário valorize-o como importante sujeito social no contexto educativo;

- respeite a dimensão kairológica / vivencial do tempo de cada aluno-educador, sem que a intencionalidade pedagógica dos formadores se sobrepuje as singularidades de cada um dos alunos-professores; - ocorra de modo integrado à prática professoral, sob a perspectiva de trabalho com projetos, situando seus alunos como sujeitos de pesquisa,

- esteja em consonância com princípios de construção colaborativa e solidária de conhecimento, que realmente agreguem valor ao educador.

Ao envolver o sujeito, num processo formativo a distância, por meio da internet, é fundamental que o seu formador (seja ele o docente ou o tutor) considere o contexto no qual o estudante está inserido e que lhe direciona a demandas específicas, bem como esteja pautado na interação coletiva como modo de construção do conhecimento. Este tipo de interação quando alicerçada na colaboração entre os participantes poderá fomentar aprendizagens extremamente ricas para todos os envolvidos.

Cabe lembrar que o que faz diferença em um curso ou programa formativo é justamente o modo como ele é conduzido pelo formador e as bases nas quais o processo se fundamenta.

É importante ainda ter em conta que "para entender o conceito e a prática da educação a distância é preciso refletir sobre o conceito mais amplo, que é o uso das (novas) tecnologias de informação e comunicação na educação" (BELLONI, 2002, p. 122).

A educação a distância tem se mostrado uma forte aliada na promoção de processos formativos de professores, especialmente com o aporte da internet. Com a internet é possível modificar com facilidade a forma de ensinar e de aprender e o professor pode se transformar em orientador da aprendizagem (MORAN, 2000) de outros e de si próprio.

As mudanças que vem ocorrendo no mundo têm provocado uma evolução tecnológica e um maior acesso à internet, isso facilitou e ampliou as possibilidades da educação a distância. Com isso, cada vez mais, programas formativos via internet vem ganhando espaço e indicando bons caminhos a se considerar na elaboração e condução de disciplinas de cursos de graduação e pós-graduação.

Marcelo García (1999) aponta a necessidade de redefinição do trabalho do professor diante das demandas atuais e aponta a importância da capacidade de inovação dentre as quais estão as novas tecnologias da informação e comunicação (TIC). Segundo ele este enfoque se ajusta as características da aprendizagem do adulto. Assim a seleção de meios e recursos deve estar baseada em uma teoria da aprendizagem, e as novas tecnologias deveriam promover a mudança no ensino e na aprendizagem, o que requer um cuidado das atividades de organização da aprendizagem dos conteúdos.

Com o advento da internet é possível modificar com facilidade a forma de ensinar e de aprender e o professor pode se transformar em orientador da aprendizagem (MORAN, 2000) de outros e de si próprio.

A cada dia novas tecnologias são criadas e com isso diversas ferramentas podem ser analisadas e adaptadas aos objetivos de ensino. Com o crescente desenvolvimento tecnológico é fundamental que o professor não se distancie desse processo e que possa ter condições de incorporar criticamente em sua prática desde as mais simples ferramentas até as mais complexas, de acordo com 
seus objetivos.

Nesse sentido vale salientar o que Almeida (2003, p. 334) entende como contribuição do ensino a distância por meio de ambientes virtuais de aprendizagem:

ensinar em ambiente digitais e interativos de aprendizagem significa: organizar situações de aprendizagem, planejar e propor atividades; disponibilizar materiais de apoio com o uso de múltiplas mídias e linguagens; ter um professor que atue como mediador e orientador do aluno, procurando identificar suas representações de pensamento; favorecer informações relevantes, incentivar a busca de distintas fontes de informações e a realização de experimentações; provocar a reflexão sobre processos e produtos; favorecer a formalização de conceitos; propiciar a interaprendizagem e a aprendizagem significativa dos aluno.

É importante destacar que a educação a distância tem se mostrado uma forte aliada no desenvolvimento de programas de formação continuada de professores, bem como na ampliação da oferta de cursos no âmbito da graduação e da pós-graduação em todo o país, permitindo, por meio sobretudo do uso da internet, o acesso rápido à informações atualizadas, interação com pessoas em qualquer lugar do mundo e a realização de cursos mais coerentes com o que se espera dos estudantes atualmente.

Um exemplo interessante é a proposta de formação continuada para professores iniciantes, desenvolvida via internet no Portal dos Professores da UFSCar. Essa experiência, pioneira no Brasil, denominada Programa de Mentoria foi desenvolvida para professores em início de carreira, sendo um excelente exemplo de como é possível formar docentes, com compromisso e qualidade com o suporte das TIC.

Referindo-se ao Programa de Mentoria, Tancredi, Reali e Mizukami (2005, p. 289) acrescentam que:

Nosso programa atende à idéia de que práticas rotineiras, descontextualizadas, que não contemplam problemas autênticos não favorecem atitudes e práticas de reflexão. Sem estas, porém, pouca mudança será possível nas práticas docentes e pequena será a autonomia dos professores para darem continuidade ao seu aprimoramento docente quando estiverem "desligados" do programa de mentoria ou sem outro apoio semelhante.

Os resultados do programa em questão apontam para a importância de investigações que focalizem os processos de aprendizagem profissional da docência de professores formadores. Embora se trate de um programa para professores da escola básica, essa experiência traz uma importante contribuição para a formação de professores e tutores, permitindo compreender as dificuldades e as necessidades formativas de ambos os grupos.

A necessidade de melhorar a formação não só do corpo docente de nossas universidades, mas também dos demais envolvidos no âmbito da $\mathrm{EaD}$, como tutores presenciais e virtuais, compõem uma demanda atual tendo em vista as especificidades dessa modalidade de ensino, sujeita às demandas atuais sobre o trabalho docente.

Outro ponto fundamental ao considerarmos a educação a distância é a gama de relações estabelecidas, formando uma grande rede, que envolve, desde professores, tutores e alunos até pessoal técnico especializado.

De modo mais específico, a atividade de tutor, seja presencial ou virtual, implica uma forma de atuação ainda um pouco indefinida quanto ao seu status e conhecimentos necessários. Os limites desta atuação, bem como o perfil e os contornos do seu trabalho são o foco de muitas discussões no meio acadêmico considerando-se as relações que estabelecem com os alunos e as que estabelecem com os próprios professores no âmbito de sua atividade.

De acordo com Abreu-e-Lima (2010) os tutores virtuais ou a distância atendem a um grupo específico de alunos, tendo como objetivo dar suporte a aprendizagem e são eles que os auxiliam nas atividades de cada disciplina, explicando como devem realizá-las, ao mesmo tempo em que dão assistência ao professor no processo de avaliação.

O desenvolvimento de uma disciplina ou curso na modalidade a distância implica a aquisição de conhecimentos específicos de como ensinar os estudantes nesse contexto, singular, que por sua vez, exige adequações no planejamento e especial atenção às potencialidades dos diversos recursos associáveis ao ambiente virtual de aprendizagem.

Essas questões se revelam muito pertinentes tanto no que se refere ao ensino presencial quanto a modalidade a distância já que em ambos os professores necessitam promover a aprendizagem dos estudantes e para isso podem fazer uso de diferentes recursos.

\section{Metodologia}

Para realização deste trabalho, utilizou-se, 
num primeiro momento, de pesquisa bibliográfica a respeito dos principais assuntos envolvidos na produção e uso dos vídeos tutoriais.

Tendo como um dos seus principais objetivos, a produção de tutoriais em vídeo para orientar a utilização de recursos educacionais pelos professores no âmbito do ensino superior e, em especial na EaD, este trabalho enfatiza o processo de produção e as potencialidades pedagógicas destes recursos.

Portanto, o desenvolvimento do projeto se deu a partir da produção de vídeos tutoriais, que seguiu diferentes etapas. A primeira foi realizada informalmente e consistiu na identificação das principais dificuldades encontradas pelos docentes relacionadas à criação e utilização de recursos educacionais. Feito isso procedeu-se a definição dos vídeos que seriam produzidos, tendo em vista o tempo disponível para implementação do projeto e, sobretudo, que não se dispunha de auxílio de pessoal especializado para prestar assessoria quanto à aspectos relacionados aos softwares e demais questões técnicas que envolviam a produção dos vídeos. Não seria possível realizar a produção de vídeos para todos os recursos disponíveis, então selecionou-se os que apresentam maior potencialidade pedagógica.

Para gravação de cada vídeo, foi necessário definir, em primeiro lugar, o que seria mostrado e como isso seria feito. Selecionou-se como recursos prioritários o blog e o vídeo, por serem os mais atrativos aos alunos e que requerem cuidados específicos importantes no momento de edição e configuração.

A seguir foram criados os roteiros de gravação contendo a ordem de captura das imagens da área de trabalho. Mesmo que após a conclusão deste processo se observem erros, é fundamental que haja um roteiro, claro e o mais detalhado possível para diminuir a incidência de problemas e imprevistos, como mudanças nos sites ou nos programas ou ainda, se esquecer de realizar algum clique. Isso mostra claramente para aquele que assiste os procedimentos a serem seguidos.

A etapa seguinte foi a produção dos vídeos tutoriais propriamente ditos. A perspectiva inicial era a produção de diversos vídeos, por categorias (vídeos para produção de RE, para inserção/utilização de RE no AVA, para utilização dos RE pelos estudantes), mas em função de dificuldades relativas a seleção dos softwares, isso não foi possível. Devido ao processo de produção ter sido todo realizado exclusivamente pela pesquisadora, optou-se por criar um vídeo integrando as informações necessárias ao professor que, posteriormente, poderá realizar cortes e adequações ao original. A etapa de seleção dos softwares foi a mais complexa e contou com a colaboração de alguns membros da equipe de suporte técnico da UAB/UFSM.

Ao mesmo tempo em que os vídeos eram produzidos eram também testados e ajustados de acordo com o que se pretendia explorar em cada um deles. Além disso, os ajustes permitem cortes quando problemas comuns como travamentos e lentidão na conexão com alguns sites acontecem.

Após a criação dos vídeos tutoriais, os mesmos foram apresentados ao público em um seminário temático.

\section{Resultados obtidos}

No que diz respeito a literatura, pouquíssimos materiais foram encontrados a respeito da utilização de vídeos tutoriais e nada foi encontrado a respeito da produção de vídeos tutoriais com o uso do sistema operacional Linux.

De modo geral, os professores contatados manifestaram dificuldades semelhantes no que se refere à criação e utilização de recursos educacionais, sendo considerados os mais difíceis de usar: vídeos, blogs e sites, externos ao AVA, e internos a este, chat, wiki e glossário.

Todo o processo de criação foi realizado tendo como princípio o uso de softwares livres, disponíveis gratuitamente na central de programas do sistema operacional Linux. A distribuição usada foi o Ubuntu 12.04, a mais atual no momento de produção do material. Os programas usados foram: Kazam Screamcaster para gravação da área de trabalho, Openshot para a edição dos vídeos, Gnome legenda para a criação e edição de legendas e o VLC, reprodutor de mídias.

Outros softwares foram testados antes dos citados acima. Todos passaram por um processo de análise e muitos foram descartados no decorrer dos testes, tendo em vista as particularidades de cada um para o atendimento do fim desejado. Esse processo foi longo e muito trabalhoso, pois alguns softwares, que inicialmente mostravam-se como os mais adequados em função de suas ferramentas, com os testes, revelaram um desempenho insatisfatório para o que se pretendia. Como o objetivo era a criação de vídeos tutoriais a partir da captura da área de trabalho, com áudio e legendas, o que parecia simples tornou-se um desafio pela necessidade de associação entre diversos softwares.

Além disso, a criação dos roteiros de gravação é um ponto essencial, sendo que quanto mais preciso for o roteiro, melhor será o resultado final 
e mais rápido ele ficará pronto. $\mathrm{O}$ roteiro deve levar em conta o tempo final que se quer para o vídeo, isso requer cronometrar cada clique, ter clareza dos passos a seguir e do necessário ajuste que será feito posteriormente com o áudio e/ou com a legenda. Um bom roteiro deve conter o texto das legendas (escritas ou faladas), bem como determinar o tempo de duração da exibição ou da leitura de cada uma delas. Com isso, a gravação transcorrerá de forma tranquila.

No momento da gravação, além de seguir cuidadosamente o roteiro definido, é importante deixar sites e programas abertos previamente para agilizar o processo e diminuir a ocorrência de possíveis travamentos. Um bom vídeo tutorial tem de mostrar a área de trabalho sendo usada, sem travamentos ou interrupções. Com o primeiro programa usado, isso não aconteceu, ao final dos testes, durante a execução do vídeo, as imagens apareciam tremidas, lentas e distorcidas. Então outros foram testados e o programa que deu melhor resultado para a gravação da área de trabalho foi o Kazam Screamcaster, um programa bastante simples e muito eficiente.

Da mesma forma, em função de seu desempenho, para a edição dos vídeos utilizou-se o programa Openshot. Este editor permite que sejam feitos cortes e adições no vídeo, bem como, inserção de efeitos especiais, áudio e legendas. Contudo, devido a complexidade da ferramenta de formatação de legendas, estas foram criadas e editadas em outro programa. A etapa mais complexa foi a sincronização das imagens com a duração do texto de cada legenda, pois foram feitos em programas separados.

Para a criação e edição de legendas utilizou-se o Gnome Legenda, por ser o mais eficiente, já que possibilita uma edição rápida das legendas, e conta com vários recursos internos de formatação do texto. Para finalizar, os vídeos foram executados no VLC, reprodutor de mídias.

Durante a fase de testagem algumas dificuldades foram encontradas quanto aos ajustes necessários para melhorar a qualidade do produto final, tanto no que se refere aos roteiros de gravação, que em determinados casos tiveram de ser reduzidos, quanto na inserção/edição das legendas.

A seleção dos programas para criação dos vídeos tutoriais foi um ponto negativo, pois demandou mais tempo do que o esperado em função da testagem de vários programas, sendo necessário compará-los e verificar todas as suas vantagens e limitações.

Por outro lado, vários foram os pontos positivos deste processo, como a possibilidade de conhecer e aprender a utilizar novos softwares, especialmente suas potencialidades para uso em diferentes projetos educacionais, o processo de criação de recursos (vídeos tutoriais) a partir da perspectiva do professor e do estudante, que implicou pensar também em diferentes atividades que podem ser propostas com um mesmo recurso.

Os vídeos tutoriais foram produzidos tendo como base dois aspectos essenciais: as possibilidades de produção de recursos educacionais pelos próprios professores e a utilização destes pelos estudantes no AVA. A produção de recursos, sobretudo vídeos e blogs, pelos próprios professores para utilização em sala de aula, presencial ou não, favorece o desenvolvimento da autonomia, não ficando este limitado ao que encontra disponível na internet ou em outros meios. Desse modo, pode proporcionar aos alunos um uso mais coerente com os conteúdos curriculares e, ainda, com a realidade vivenciada por eles fora do espaço de aula. Assim, dentre os principais resultados obtidos estão os próprios recursos produzidos, já que podem orientar professores na criação de vídeos explicativos materiais e atividades mais adequados para conteúdos específicos.

\section{Considerações finais}

O acompanhamento dos procedimentos de criação de um recurso, seja ele um blog, um vídeo, um site, um chat, etc, por meio de um vídeo tutorial, pode auxiliar muito na execução correta das operações (passo-a-passo) por quem assiste a ele, sendo uma das suas principais vantagens quando se espera facilitar a aprendizagem dos alunos. Com os vídeos tutoriais é possível visualizar todo o processo por etapas, podendo a qualquer momento interromper a exibição do vídeo para verificar algo que tenha dúvida. O estudante pode ainda assisti-lo quantas vezes forem necessárias para a compreensão de um conteúdo ou procedimento.

Já o professor, especialmente aquele que atua na educação a distância, tem em suas mãos uma excelente ferramenta para orientar os estudantes no que se refere a como participar de um fórum no AVA, por exemplo, ou como criar e usar um blog, fora do ambiente virtual. Os vídeos tutoriais podem ainda ser usados pelo professor para complementar uma explicação dada em sala de aula, para facilitar a compreensão de um conteúdo específico a partir de imagens ou animações com suporte de legenda ou áudio. 
É de extrema importância que os professores aprendam a criar suas próprias ferramentas, tendo em conta, entre outros aspectos, a especificidade de cada turma, as características individuais de aprendizagem dos estudantes, e, alguma eventual necessidade educacional especial.

Os recursos educacionais, especialmente vídeo, imagem e áudio, se somam nos vídeos tutoriais e explicitam a sua relevância tendo em vista a necessidade de se apresentar materiais em diferentes formatos aos professores para que estes, por sua vez, também busquem inserir em seus planejamentos novos e diversificados recursos e, com isso, favoreçam a construção do conhecimento de todos os seus estudantes.

Espera-se que este trabalho e os vídeos produzidos possam contribuir para uma maior autonomia dos professores na produção e utilização de recursos educacionais. Espera-se ainda que tais recursos sejam capazes de proporcionar maior interação e colaboração entre os próprios estudantes, ampliando seus conhecimentos.

Os vídeos tutoriais se constituem como importantes ferramentas para aprendizagem e autonomia dos professores tanto na modalidade a distância quanto no presencial, pois orientam a criação e a utilização de recursos ricos e pouco explorados e, que se bem articulados com outros recursos do próprio Moodle, podem auxiliar na elaboração de atividades mais dinâmicas e atrativas aos estudantes.

\section{ReFERÊNCIAS BIBLIOGRÁfICAS}

ABREU-E-LIMA, D. M. de. As habilidades e as inteligências do tutor virtual no trabalho em EaD. Disponível em: http://www.abed.org.br/congresso2010/ cd/252010193836.pdf. Acesso em: 05/12/2010.

ALMEIDA, M. E. B. Educação a distância na internet: abordagens e contribuições dos ambientes digitais de aprendizagem. Educação e pesquisa, v29, n2, p.327-340, Jul/dez, 2003.

BELLONI, M. L. Ensaio sobre a educação a distância no brasil. Educação \& Sociedade, ano XXIII, n. 78, 2002, p.117-142

MARCELO GARCÍA, C. La Formación de los formadores como espacio de trabajo e investigación: dos ejemplos. XXI Revista de Educación, ${ }^{\circ} 1$, p. 33-57,1999.
REALI, A.M.M.R.; MIZUKAMI, M.G.N. Construindo a base de conhecimento profissional da docência: contribuições do uso de histórias e narrativas. In: MIZUKAMI, M.G.N.; REALI, A.M.M.R. Processos formativos da docência. EDUFSCAR, 2005. p.121-142.

SHULMAN, L. Those who understands: knowledge growth in teaching. Educational Researcher, v. 15, n. 2, 1986. p. 4-14.

SHULMAN, L. Knowledge and teaching: the foundations of the new reform. Harvard Educational Review, v.57, n1, 1987, p. 1-21.

MORAN, J.M. Ensino e aprendizagem inovadores com tecnologias. Informática na Educação: Teoria \& Prática. Porto Alegre, vol. 3, n.1 (set. 2000) UFRGS. Programa de Pós-Graduação em Informática na Educação, p. 137-144.

PEDROSA, Stella Maria Peixoto de Azevedo. A educação a distância na formação continuada do professor. Educar, Curitiba, n. 21, p. 67-81. 2003. Editora UFPR, 2003

PESCE, L. M. Educação a distância: novas perspectivas à formação de educadores. In: MORAES, M. C. (Org.) Educação a distância: fundamentos e práticas. Campinas. UNICAMP/NIED, 2002. p. 91-104.

TANCREDI, R. M. S. P.; REALI, A. M. M. R; MIZUKAMI, M. G. N. Relatório de pesquisa (FAPESP/Ensino Público), 2005.

VAILLANT, D. Formação de formadores: estado da prática. PREAL. Programa de Promoção da Reforma Educativa na América Latina e Caribe. n. 25, 2003. Disponível em www[1].preal.cl-public-dtindex.php. Acesso em 25/04/2006. 